\title{
Using Colloidal Nano Silica to Enhance the Performance of Cementitious Mortars
}

\author{
Achraf Ayad, Aly Said \\ Faculty of Engineering, Department of Architectural Engineering, The Pennsylvania State University, Pennsylvania, USA \\ Email: aly.said@engr.psu.edu
}

How to cite this paper: Ayad, A. and Said A. (2018) Using Colloidal Nano Silica to Enhance the Performance of Cementitious Mortars. Open Journal of Civil Engineering, 8, 82-90. https://doi.org/10.4236/ojce.2018.81007

Received: February 1, 2018

Accepted: March 20, 2018

Published: March 23, 2018

Copyright (C) 2018 by authors and Scientific Research Publishing Inc. This work is licensed under the Creative Commons Attribution International License (CC BY 4.0).

http://creativecommons.org/licenses/by/4.0/

(c) (i) Open Access

\begin{abstract}
Nanomaterials have been widely used in the past few decades due to their proven capacity to enhance the mechanical properties of materials. While many studies have sought to improve the understanding of how nanomaterials affect the behavior of concrete, additional research is needed in order to achieve the full potential of the material, especially in the presence of supplementary cementitious materials. This study aims to investigate the mechanical properties of cement mortars incorporating both nano-silica (NS) and class F fly ash (FA). Furthermore, mercury intrusion porosimetry (MIP) was performed to study its effect on pore characteristics, and thermogravimetric analysis (TGA) was performed to measure the calcium hydroxide $\mathrm{Ca}(\mathrm{OH})_{2}$ content in the mixtures. It was found that using nano-silica enhances the compressive strength, reduces the total porosity and accelerates the pozzolanic reaction.
\end{abstract}

\section{Keywords}

Colloidal Nano Silica, Nano Silica, Concrete, Mortar, MIP, TGA

\section{Introduction}

The use of supplementary cementitious materials (SCM) reduces the embodied energy in concrete considerably. Furthermore, it significantly improves the durability of concrete and increases its lifecycle thus leading to a more sustainable design. However, despite the available literature on nanotechnology and its applications in the construction industry, further research is needed on the effect of using nano silica (NS) in concrete, especially when combined with SCMs. Fly ash is the most commonly used supplementary cementitious material in the cement industry because of its various advantages like increased flowability [1], and strength gain at later ages. However, fly ash slows the setting time and the 
strength gain at early ages [2] [3].

Researchers have examined the effects of using NS in pastes [4], mortars [5] and concrete [6] [7]. The majority of these studies found that using small dosages of NS improves the early age and the 28-day strength, which is attributed to pore refinement and to the enhanced characteristics of the interfacial transition zone between paste and aggregate. However, inadequate dispersion of NS can lead to agglomeration, which can drastically reduce the benefits of using NS especially at early age [8]. Also, very few researchers examined the combined effect of using both NS and fly ash especially in terms of porosity and pozzolanic activity. This paper aims to investigate the combined effect of using NS and fly ash on cement mortars' compressive strength, porosity and pozzolanic activity.

\section{Experimental Program}

\subsection{Materials}

Colloidal NS was used in the form of an alkaline aqueous solution with $50 \%$ silica by weight. The nano-silica dispersion was sodium stabilized and the particles have a negative surface charge. The properties are tabulated in Table 1 . Class $\mathrm{F}$ fly ash conforming to ASTM C 618 [9] was used, and type I ordinary portland cement (OPC). In this study, the performance of cement mortars containing class $\mathrm{F}$ fly ash will be assessed in the presentence of colloidal nano-silica. Three main groups are tested with: $0 \%, 25 \%$, and 35\% FA replacements. In each of these groups $0 \%, 2 \%$, and $4 \%$ NS replacements are investigated as shown in Table 2.

Table 1. Properties of NS.

\begin{tabular}{cc}
\hline Nano-Silica, wt (\%) & 50 \\
\hline $\mathrm{pH}$ & 9 \\
Viscosity, cP & 15 \\
Density, g/cm & 1.4 \\
$\mathrm{Na}_{2} \mathrm{O}, \mathrm{wt}(\%)$ & 0.4 \\
\hline
\end{tabular}

Table 2. Proposed test matrix.

\begin{tabular}{ccccc}
\hline & & \multicolumn{3}{c}{ binder percentage } \\
\cline { 3 - 5 } Group number & Mixture ID & OPC & Fly ash & CNS \\
\hline Group 1 & OPC & 100 & 0 & 0 \\
& NS1 & 98 & 0 & 2 \\
Group 2 & NS2 & 96 & 0 & 4 \\
& FA1 & 75 & 25 & 0 \\
Group 3 & NF2 & 73 & 25 & 4 \\
& FA2 & 71 & 25 & 0 \\
& NF11 & 65 & 35 & 2 \\
& NF22 & 63 & 35 & 4
\end{tabular}




\subsection{Testing Methods}

The compressive strength gain of different mortars was assessed by testing standard cubes following ASTM C 109 [10]. The mortar cubes were cured in a lime bath until the age of testing in order to prevent calcium leaching. Furthermore, the pore properties of the matrix were evaluated using mercury intrusion porosimetry (MIP). And finally, in order monitor the progress of the pozzolanic reaction, thermogravimetric analysis (TGA) was used to quantify the amount of calcium hydroxide $\left(\mathrm{Ca}(\mathrm{OH})_{2}\right)$ in the system. The consumption of calcium hydroxide is a direct indication for the progress of the pozzolanic reaction in the presence of FA and NS after accounting for carbonation [11].

\section{Results and Discussions}

\subsection{Compressive Strength}

Colloidal NS improved the compressive strength of mortar in all groups. With no FA replacement, introducing $2 \%$ and $4 \%$ NS improved the compressive strength from $6.54 \mathrm{ksi}$ to $7.37 \mathrm{ksi}$ and $7.71 \mathrm{ksi}$, respectively. With $25 \%$ FA replacement, the addition of $2 \%$ and $4 \%$ NS enhanced the compressive strength from $6.68 \mathrm{ksi}$ to $7.14 \mathrm{ksi}$ and $7.23 \mathrm{ksi}$, respectively. Finally, for 35\% FA replacement, the addition of $2 \%$ and $4 \%$ NS improved the compressive strength from $6.48 \mathrm{ksi}$ to $6.56 \mathrm{ksi}$ and $6.93 \mathrm{ksi}$, respectively. These results are illustrated separately in Figure 1. The three groups are separated to observe the improvement caused by NS within each group where the FA replacement is constant and not between different percentages of FA.

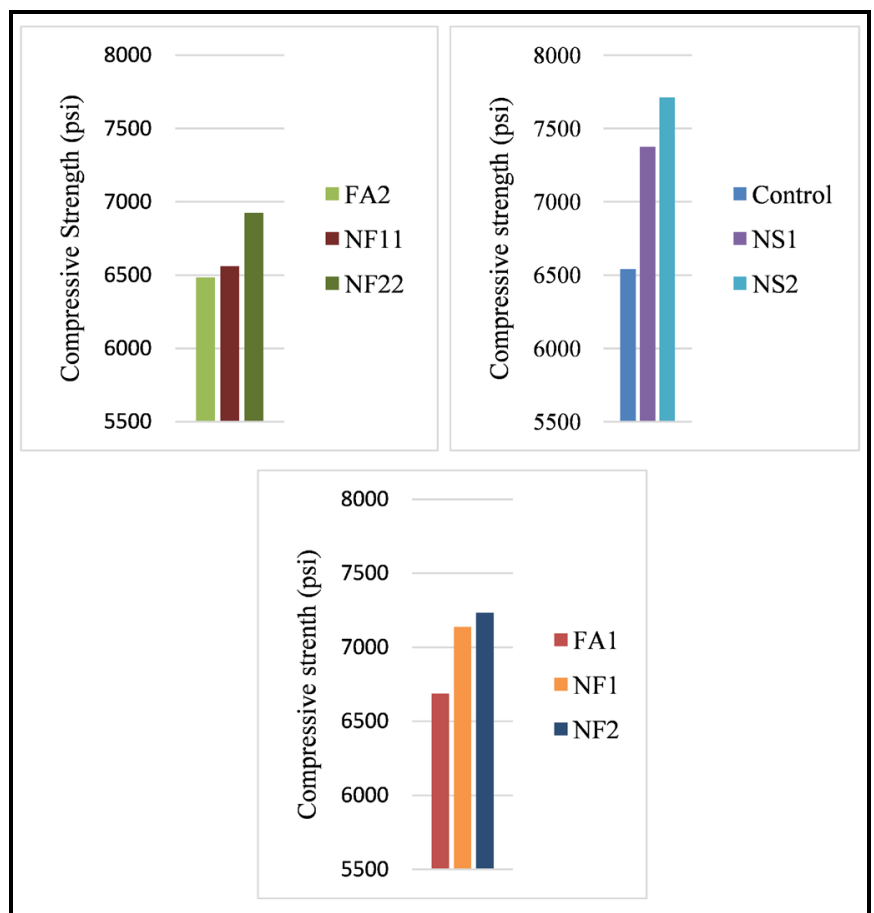

Figure 1. Compressive strength of the tested mortar mixtures. 
The observed improvement in compressive strength can be attributed to the accelerated pozzolanic reaction in the presence of NS along with a decreased porosity which will be discussed in the next section. The NS reacts with calcium hydroxide to produce calcium-silicate-hydrate (C-S-H). A smaller amount of calcium hydroxide is available in the mixtures containing FA since cement, the source of calcium silicates that react with water to form calcium hydroxide, is being partially replaced by FA. Accordingly, more calcium hydroxide is converted into $\mathrm{C}-\mathrm{S}-\mathrm{H}$ in the absence of $\mathrm{FA}$ which increases the relative improvement of strength between groups. Namely, in Group 1 where there is no FA replacement, a larger improvement in the compressive strength is observed when NS is added with respect to the control specimen whereas when NS is added to Groups 2 and 3, less improvement in $f_{c}^{\prime}$ is observed in NF1, NF2, NF11, and NF22 when compared to FA1 and FA2 respectively. Furthermore, FA is known to refine the porosity of concrete [12]. Accordingly, while NS generally reduces the porosity, a smaller reduction in porosity is expected when NS is introduced in the FA based groups when compared to the group not containing FA after the introduction of NS.

\subsection{Mercury Intrusion Porosimetry}

Mercury intrusion porosimetry can be utilized to study the pore distribution of hardened cementitious materials over a range going from a few hundred microns to as small as few nanometers. In the MIP test, mercury is pressured to fill pores in the samples. As a non-wetting liquid, mercury does not naturally penetrate the pores and, therefore, the pressure required to force it into the pores can be correlated to the corresponding pore volume in the form:

$$
|2 \gamma \cos \theta|=\operatorname{Pr}
$$

where $\gamma$ is the surface tension of mercury, $\theta$ is the angle of contact, $P$ is the pressure and $r$ is pore radius. Subsequently, the recorded values are plotted in the form of a curve that traces the cumulative pore volume versus pressure. While this method is quite popular, it has some drawbacks pertaining to the assumptions made in order to get the total porosity. Particularly assuming constant surface tension within the sample and ignoring pore irregularity [10].

Using MIP, the measured average porosity of mortar samples decreased for all categories in the presence of NS. This can be attributed to the filler effect where the small NS particles fill smaller pores that cannot be filled by relatively larger cement particles, sand, or FA particles. Decreasing the porosity of samples leads to an increase in the compressive strength and a reduction of potential environmental deteriorations. The average pore diameters for all samples are illustrated in Figure 2.

Furthermore, as shown in Figure 3, introducing 2\%, and 4\% NS replacements results in a reduction in the total porosity and smaller-sized pores in Group 1 with respect to the samples that had $25 \%$ and $35 \%$ FA replacement. However, 


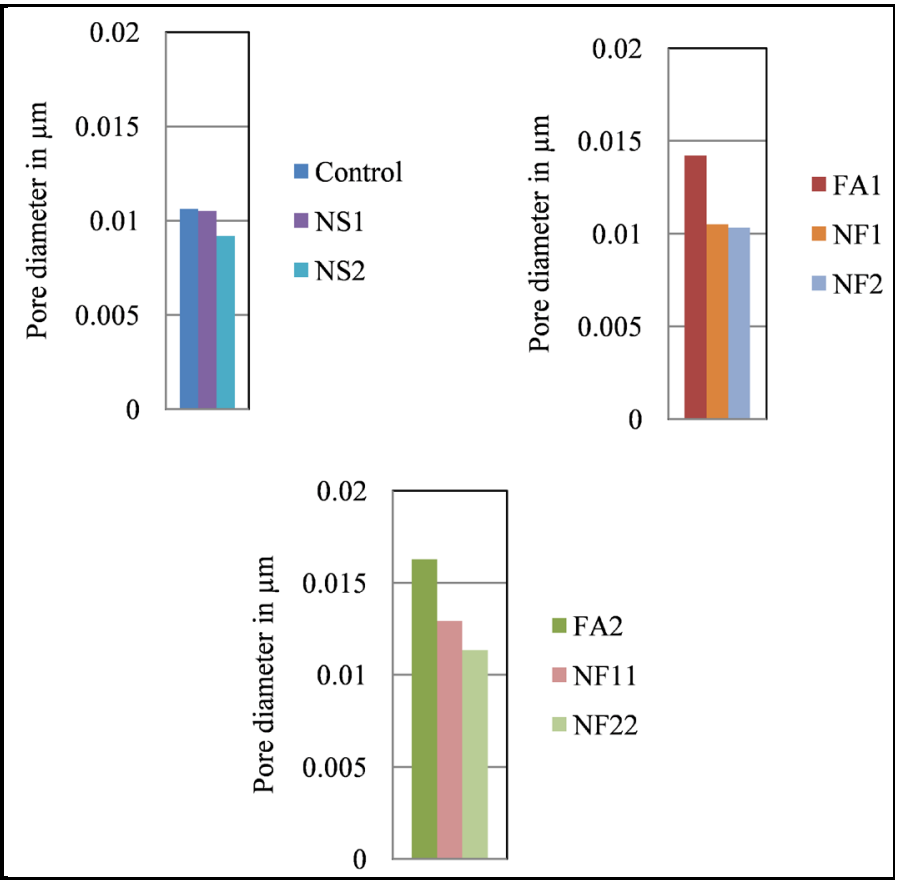

Figure 2. Average pore diameter as measured by MIP.

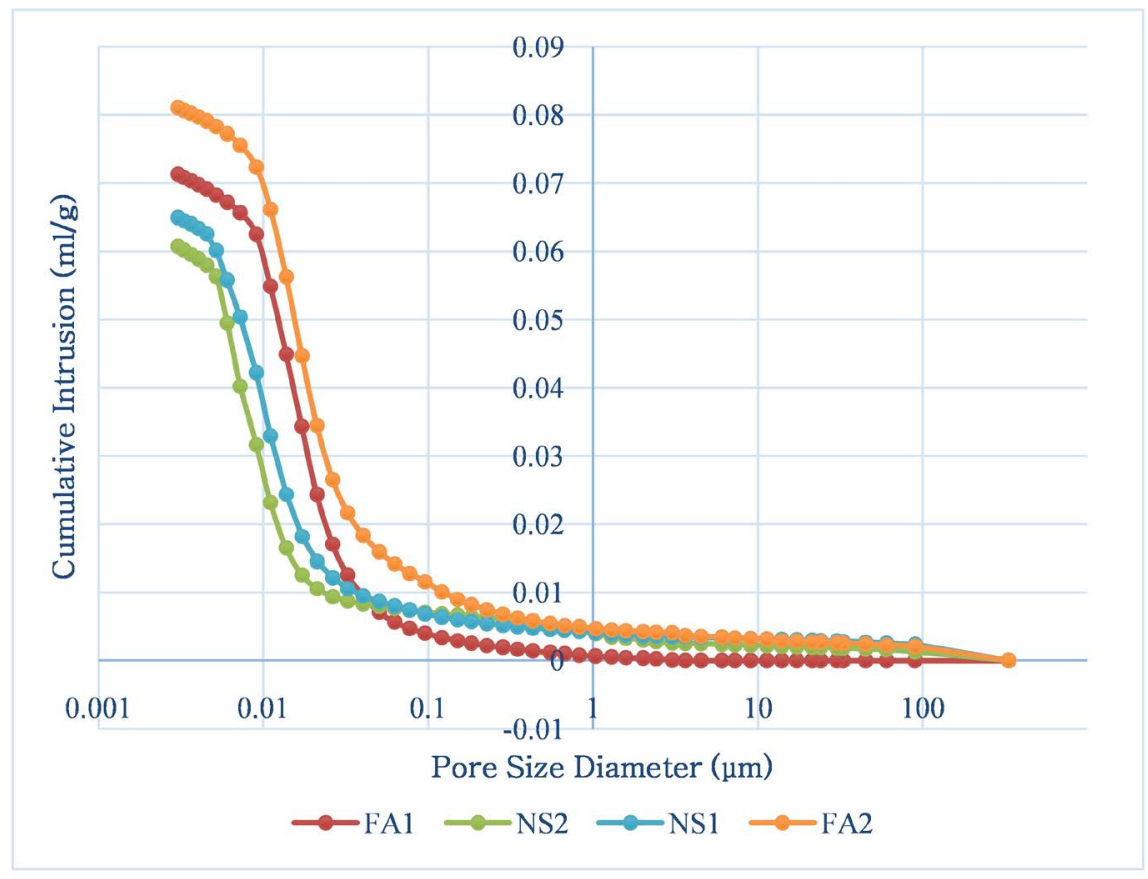

Figure 3. Pore size distribution of tested mortar mixtures.

larger-sized pores are observed with the NS samples, an indication of potential agglomeration. Many of the benefits of NS can be compromised by agglomeration [11]. And sonication or better dispersion techniques should be introduced to prevent agglomeration that compromises enhancements in porosity and compressive strength. 


\subsection{Thermogravimetric Analysis}

Thermogravimetric analysis was performed on paste rather than mortar. This was done to eliminate any impurities that may be introduced by sand. Closed plastic containers were used to mold the paste and parafilm was also used under the lid to prevent any carbonation. The impermeable containers were then kept at a room temperature of $24^{\circ} \mathrm{C}$. At the time of testing, the samples were removed from the plastic containers, ground using a mortar and pestle to pass sieve \#200. Consequently, the powder was placed in the TGA under an inert gas $\left(\mathrm{N}_{2}\right)$ to dry at $100^{\circ} \mathrm{C}$. After drying the sample and the weight loss stops, the sample is heated again at $15^{\circ} \mathrm{C} / \mathrm{min}$ and the weight loss was recorded. Additionally, the first derivative of the TG curve (DTG) is recorded with respect to temperature. Each peak in the DTG curve indicates a different phase and the mass loss in that region can be used to quantify the phase in question. In this study, $\mathrm{Ca}(\mathrm{OH})_{2}$ is of interest and any $\mathrm{Ca}(\mathrm{CO})_{3}$ resulting from carbonation. This is typically found between $400^{\circ} \mathrm{C}$ and $550^{\circ} \mathrm{C}$ and can be precisely detected by following the DTG peaks [13]. A reduction in the amount of $\mathrm{Ca}(\mathrm{OH})_{2}$ with respect to the control specimen is a direct indication of the progress of the pozzolanic reaction. This method has been widely used to qualitatively and quantitatively measure $\mathrm{Ca}(\mathrm{OH})_{2}$ and the additional C-S-H formed [14] [15] [16].

NS decreases the content of $\mathrm{Ca}(\mathrm{OH})_{2}$ for all groups at all ages as shown in Figures 4-6. This reduction in the amount of calcium hydroxide is very beneficial because it indicates the progress of the pozzolanic reaction and the production of additional C-S-H. In addition to the improved mechanical characteristics caused by C-S-H, low calcium hydroxide content reduces the potential for alkali-silica reactions where calcium is a vital element for that reaction [17]. While calcium hydroxide slightly contributes to the overall strength of cement mortars by growing in available spaces and reducing the porosity, it has a general detrimental effect on the durability of the cementitious matrix. It is more soluble than C-S-H and leaching of calcium hydroxide can increase the permeability of the mortar and increase its vulnerability to environmental agents [18].

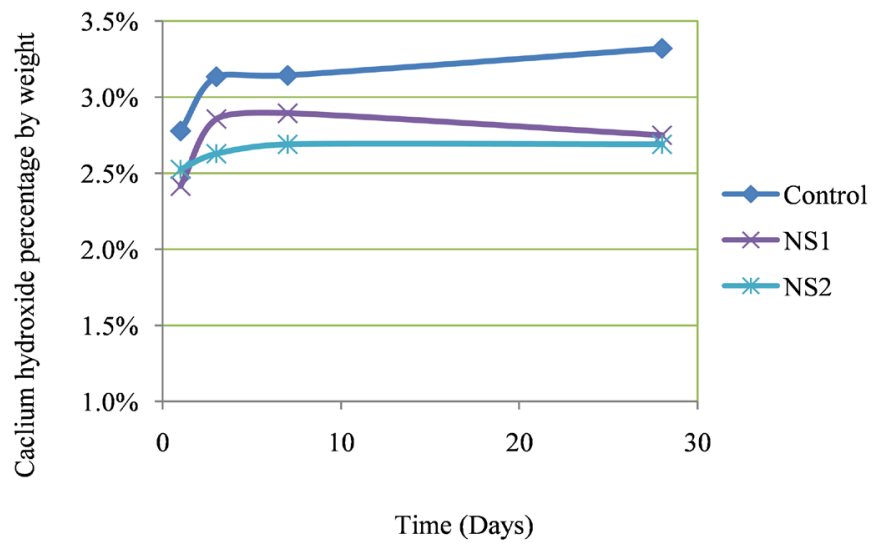

Figure 4. Calcium hydroxide content for Group 1. 


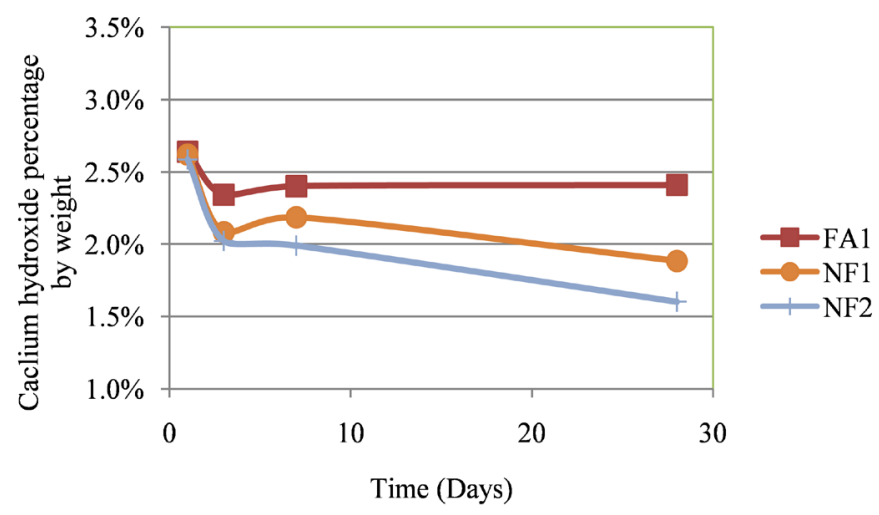

Figure 5. Calcium hydroxide content for Group 2.

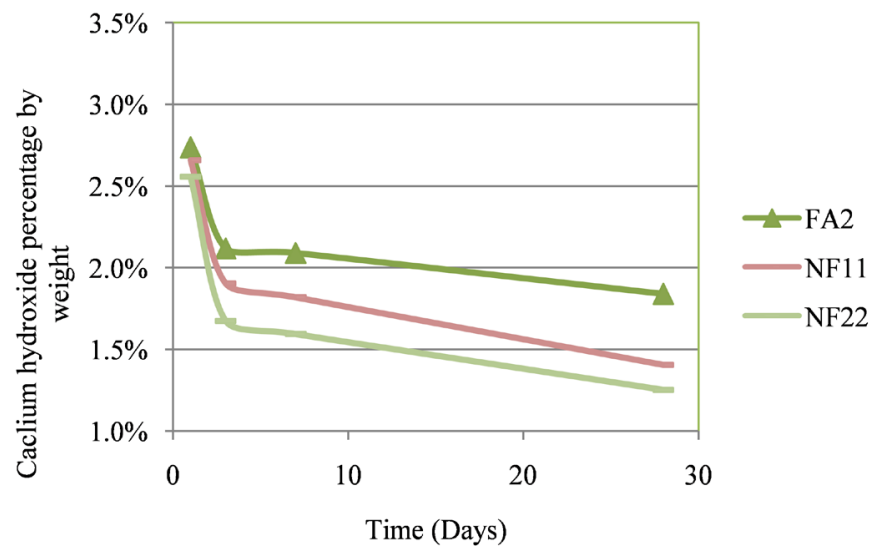

Figure 6. Calcium hydroxide content for Group 3.

\section{Conclusions}

The current study assessed the influence of colloidal NS on cement mortars in 3 separate groups that contained $0 \%, 25 \%$ and $35 \%$ FA replacements respectively. And the following conclusions are drawn:

- The use of colloidal NS improves the compressive strength of all mortar groups, but it is most effective in the groups not containing FA. This improvement is attributed to the accelerated pozzolanic reaction and the filler effect.

- The use of colloidal NS reduces the average pore diameter for all mixtures, the small particle size of NS helped reduce the amount of small pores but additional large-sized pores are observed which may be attributed to agglomeration.

- Colloidal NS reduces the amount of calcium hydroxide in the mixtures and is therefore efficient in converting calcium hydroxide into calcium silicate hydrate and in enhancing the pozzolanic reaction even at early age.

Since potential signs of agglomeration were observed in the form of large pores, it is important to emphasize the need for dispersion thorough available methods including sonication or high energy mixing for best results. Also, Scanning Electron Microscopy (SEM) and other techniques could be used in order to 
verify the results and add more details about the hydration process and chemical composition of the resulting mixture.

\section{References}

[1] Şahmaran, M., Yaman, İ.Ö. and Tokyay, M. (2009) Transport and Mechanical Properties of Self Consolidating Concrete with High Volume Fly Ash. Cement and Concrete Composites, 31, 99-106.

https://doi.org/10.1016/j.cemconcomp.2008.12.003

[2] Bentz, D.P., Barrett, T., De, I. and Weiss, W.J. (2012) Relating Compressive Strength to Heat Release in Mortars. Advances in Civil Engineering Materials, 1, 14 p. https://doi.org/10.1520/ACEM20120002

[3] Lam, L., Wong, Y.L. and Poon, C.S. (2000) Degree of Hydration and Gel/Space Ratio of High-Volume Fly Ash/Cement Systems. Cement and Concrete Research, 30, 747-756. https://doi.org/10.1016/S0008-8846(00)00213-1

[4] Qing, Y., Zenan, Z., Deyu, K. and Rongshen, C. (2007) Influence of Nano-SiO $\mathrm{S}_{2} \mathrm{Ad}$ dition on Properties of Hardened Cement Paste as Compared with Silica Fume. Construction and Building Materials, 21, 539-545. https://doi.org/10.1016/j.conbuildmat.2005.09.001

[5] Li, H., Xiao, H., Yuan, J. and Ou, J. (2004) Microstructure of Cement Mortar with Nano-Particles. Composites Part B: Engineering, 35, 185-189. |https://doi.org/10.1016/S1359-8368(03)00052-0

[6] Schoepfer, J. and Maji, A. (2009) An Investigation into the Effect of Silicon Dioxide Particle Size on the Strength of Concrete. Special Publication, 267, 45-58.

[7] Said, A.M., Zeidan, M.S., Bassuoni, M.T. and Tian, Y. (2012) Properties of Concrete Incorporating Nano-Silica. Construction and Building Materials, 36, 838-844. https://doi.org/10.1016/j.conbuildmat.2012.06.044

[8] Kong, D., Du, X., Wei, S., Zhang, H., Yang, Y. and Shah, S.P. (2012) Influence of Nano-Silica Agglomeration on Microstructure and Properties of the Hardened Cement-Based Materials. Construction and Building Materials, 37, 707-715. https://doi.org/10.1016/j.conbuildmat.2012.08.006

[9] ASTM Standard C618 (2017) Specification for Coal Fly Ash and Raw or Calcined Natural Pozzolan for Use in Concrete. ASTM International, West Conshohocken, PA. https://www.astm.org/

[10] ASTM C109/C109M (2016) Standard Test Method for Compressive Strength of Hydraulic Cement Mortars (Using 2-in. or [50-mm] Cube Specimens). ASTM International, West Conshohocken, PA. https://www.astm.org/

[11] Pane, I. and Hansen, W. (2005) Investigation of Blended Cement Hydration by Isothermal Calorimetry and Thermal Analysis. Cement and Concrete Research, 35, 1155-1164. https://doi.org/10.1016/j.cemconres.2004.10.027

[12] Lothenbach, B., Scrivener, K. and Hooton, R.D. (2011) Supplementary Cementitious Materials. Cement and Concrete Research, 41, 1244-1256. https://doi.org/10.1016/j.cemconres.2010.12.001

[13] Kim, T. and Olek, J. (2012) Effects of Sample Preparation and Interpretation of Thermogravimetric Curves on Calcium Hydroxide in Hydrated Pastes and Mortars. Transp. Transportation Research Record: Journal of the Transportation Research Board, 2290, 10-18. https://doi.org/10.3141/2290-02

[14] Singh, L.P., Goel, A., Bhattacharyya, S.K., Sharma, U. and Mishra, G. (2015) Hydra- 
tion Studies of Cementitious Material Using Silica Nanoparticles. Journal of Advanced Concrete Technology, 13, 345-354.

[15] Lam, L., Wong, Y. and Poon, C. (2000) Degree of Hydration and Gel/Space Ratio of High-Volume Fly Ash/Cement Systems. Cement and Concrete Research, 30, 747-756. https://doi.org/10.1016/S0008-8846(00)00213-1

[16] Chaipanich, A. and Nochaiya, T. (2010) Thermal Analysis and Microstructure of Portland Cement-Fly Ash-Silica Fume Pastes. Journal of Thermal Analysis and Calorimetry, 99, 487-493. https://doi.org/10.1007/s10973-009-0403-y

[17] Wang, H. and Gillott, J.E. (1991) Mechanism of Alkali-Silica Reaction and the Significance of Calcium Hydroxide. Cement and Concrete Research, 21, 647-654. https://doi.org/10.1016/0008-8846(91)90115-X

[18] Mindess, S., Young, J.F. and Darwin, D. (2003) Concrete. Pearson Education, Upper Saddle River, NJ. 